\title{
New seminal variety of Stevia rebaudiana: Obtaining fractions with high antioxidant potential of leaves
}

\author{
PAULA G. MILANI ${ }^{1}$, MAYSA FORMIGONI ${ }^{1}$, ANTONIO S. DACOME ${ }^{2}$, LIVIA \\ BENOSSI $^{1}$, CECÍLIA E.M. DA COSTA ${ }^{3}$ and SILVIO C. DA COSTA ${ }^{2}$
${ }^{1}$ State University of Maringa, Postgraduate Program in Food Science, Av. Colombo, 5790, Jardim Universitário, 87020-900 Maringá, PR, Brazil
${ }^{2}$ State University of Maringa, Department of Biochemistry, Av. Colombo, 5790, Jardim Universitário, 87020-900 Maringá, PR, Brazil
${ }^{3}$ State University of Maringa, Department of Physiological Sciences, Av. Colombo, \\ 5790, Jardim Universitário, 87020-900 Maringá, PR, Brazil
}

Manuscript received on March 10, 2017; accepted for publication on April 6, 2017

\begin{abstract}
The aim of this study was to determine the composition and antioxidant potential of leaves of a new variety of Stevia rebaudiana (Stevia UEM-13). Stevia leaves of UEM-13 contain rebaudioside A as the main glycoside, while most wild Stevia plants contain stevioside. Furthermore can be multiplied by seed, which reduces the cost of plant culture techniques as other clonal varieties are multiplied by buds, requiring sophisticated and expensive seedling production systems. Ethanol and methanol were used in the extraction to determine the bioactive compounds. The methanolic extract was fractionated sequentially with hexane, chloroform, ethyl acetate and isobutanol, and the highest concentration of phenolic compounds and flavonoids was obtained in the ethyl acetate fraction (524.20 mg galic acid equivalent/g; $380.62 \mu \mathrm{g}$ quercetin equivalent $/ g)$. The glycoside content varied greatly among the fractions $(0.5 \%-65.3 \%)$. Higher antioxidant potential was found in the methanol extract and the ethyl acetate fraction with $93.5 \%$ and $97.32 \%$, respectively. In addition to being an excellent source for obtaining of extracts rich in glycoside, this new variety can also be used as raw material for the production of extracts or fractions with a significant amount of antioxidant activity and potential to be used as additives in food.
\end{abstract}

Key words: Bioactive compounds, glycosides, leaf extracts, phenolic compounds, new cultivar of Stevia.

\section{INTRODUCTION}

Plants are an important source of structurally different active natural products and biological properties. These active ingredients can play adjuvant and important roles in traditional medicine in many countries (Tadhani and Subhash

Correspondence to: Paula Gimenez Milani

E-mail: paulinhauem@gmail.com
2007). The beneficial effects are produced by different active ingredients and other compounds of low molecular weight such as vitamins, carotenoids, flavonoids, anthocyanins, tannins and other phenolic compounds (Wölwer-Rieck 2012, Tadhani and Subhash 2007), which have different mechanisms of action. It is known that phenolic compounds and flavonoids are important for the 
normal development and protection of plants (Wölwer-Rieck 2012), but their high antioxidant activity as food additives for humans must still be further investigated.

Stevia rebaudiana Bertoni, a plant from the Asteraceae family, is native to Paraguay and it is cultivated in many countries, including Brazil, Argentina, Japan, China, the United States and European countries (Dacome et al. 2005). It is important in the food industry because the leaves contain sweet-tasting diterpene glycosides, among which stevioside and rebaudioside A (RebA) are included (Carakostas et al. 2008). These glycosides are 450 times sweeter than sucrose (Williams and Burdock 2009), which has led to commercial interest, mainly for food and beverages. The Stevia plants have more than 100 compounds (WölwerRieck 2012) and extracts from the leaves have been traditionally used in the treatment of diseases such as diabetes (Tadhani and Subhash 2007, Shukla et al. 2009). Stevia extracts can exert beneficial effects on human health, including anti-hypertension (Chan et al. 2000) and anti-hyperglycemic effects (Abudula et al. 2008), antiviral activities against the human rotavirus, it is not cariogenic and has beneficial properties for glucose metabolism and renal function (Shukla et al. 2009). The beneficial effects of these compounds on human health have been previously studied. Research aimed at obtaining Stevia extracts containing significant levels of sweeteners and these compounds (Gawel-Beben et al. 2015, Kawshik et al. 2010). The results showed that there is still no consensus on the ideal method of obtaining both compounds (sweeteners and bioactive compounds) in significant concentrations.

The composition of Stevia leaf extracts and the concentration of these bioactive compounds vary according to the solvents used and the different types of extraction methods. Significant results were found in the ethanol and methanol extracts and ethyl acetate solvents (Wölwer-Rieck 2012, Shukla et al. 2009). However, further studies should be conducted on different varieties of plants and improved extraction methods need to be developed for better results. In addition, more studies should be conducted in order to obtain the best method and the best fractions of the bioactive compounds from stevia are present in higher concentrations. The Center for Studies in Natural Products (NEPRON), State University of Maringá (UEM) started in 1990 studies in order to obtain sweeteners or stevia extracts with high levels of RebA, sweetener better sensory profile that stevioside. The first projects ("Biotechnological Applications of Stevia rebaudiana Products (Bert.) Bertoni”) resulted in the development of a selection of stevia plants with high content of this glycoside. The research resulted in obtaining two varieties (M1 Alvarez and Stevia UEM-320, the latter forward three times as RebA compared with a variety of wild-type plant, and therefore the majority glycoside in the plant selected (Alvarez and Couto 1994).

The cultivation of these clonal varieties, made by cutting method, presented some disadvantages over the years, as difficulties and rooting problems, increased susceptibility to environmental variations and attack predators, and need maintenance ideal conditions for plant growth. Currently the researchers NEPRON are developing projects in order to obtain varieties of stevia third generation that can be reproduced and grown for seed minimizing costs, increasing the viability of farming, reproducibility and marketing, and decreasing the mortality of plants. Thus, this study was developed from a new seminal variety of Stevia rebaudiana called Stevia UEM-13.

The aim of this study was to present the glycoside composition, bioactive compounds and antioxidant potential of leaves from a new variety of Stevia rebaudiana (Stevia UEM-13). Was evaluated the concentration of these bioactives in different extracts and fractions produced by different extraction methods, and also identified in which these fractions have greater functional 
potential for use in food, pharmaceutical and cosmetic products

\section{EXPERIMENTAL SECTION}

\section{EXPERIMENTAL MATERIAL}

The plants of Stevia rebaudiana of the seminal variety UEM-13 grown at NEPRON (UEM) were collected at maximum vegetative growth stage. These shrubs were previously dried in an oven at $60^{\circ} \mathrm{C}$ and the leaves were subsequently separated from the stems and branches, placed in polyethylene bags, and stored at $-18^{\circ} \mathrm{C}$ before developing different extracts. The chemical reagents were purchased from Sigma-Aldrich.

\section{AQUEOUS EXTRACT FROM THE STEVIA LEAVES UEM-13}

A 2.0 g sample of previously ground Stevia leaves UEM-13 were transferred to a $250 \mathrm{ml}$ beaker; 100 $\mathrm{mL}$ of deionized distilled water was added and boiled for five minutes. After this procedure, the material was decanted and filtered under vacuum. The procedure was repeated twice with $100 \mathrm{ml}$ and $50 \mathrm{ml}$ of water, respectively. After the last filtration, the extract was transferred to a $250 \mathrm{ml}$ volumetric balloon and filled up with distilled water. We used this extract to analyze glycosides, phenolic compounds and flavonoids.

\section{Ethanol extract of leaves by maceration (EELM)}

The extraction system was established using 500 $\mathrm{g}$ of previously ground Stevia rebaudiana leaves of the seminal variety UEM-13, placed in a 2.0 L glass beaker and 1.5 L of P.A absolute ethanol (99.5\%) was added. The system stood for 24 hours in the dark at room temperature, to obtain the first fraction. The same procedure was repeated to obtain 7 fractions (extraction until exhaustion). The extracts were combined and dried in a rotary evaporator (Buchi brand) at $50^{\circ} \mathrm{C}$ under vacuum. The powder obtained was used to evaluate the glycosides, phenolic compounds, total flavonoids and antioxidant activity.

Ethanol extract of the leaves by Soxhlet (EELS)

The previously dried and ground Stevia rebaudiana leaves (100 g) of the seminal variety UEM-13 were placed in $500 \mathrm{ml}$ of absolute ethanol (99.5\%) and added to the system using the Soxhlet apparatus. The extract was filtered and dried in a rotary evaporator (Buchi trademark) at $50^{\circ} \mathrm{C}$ under vacuum and the dry powder was analyzed.

\section{Methanol extract of the leaves by Soxhlet (MELS)}

The previously dried and ground Stevia rebaudiana leaves $(100 \mathrm{~g})$ of the seminal variety UEM-13 were placed in $500 \mathrm{ml}$ of P.A methanol and added to the system using the Soxhlet apparatus (extraction until exhaustion). The extract was filtered and dried in a rotary evaporator (Buchi brand) at $50^{\circ} \mathrm{C}$ under vacuum and the powder was analyzed.

Extract fractionated with different solvents

The fractionation was performed as follows, as shown in figure 1:

\section{Hexane fraction $(H F)$}

A $100 \mathrm{~g}$ sample of dried Stevia rebaudiana leaves of the seminal variety UEM-13 were extracted with $400 \mathrm{ml}$ of methanol were packaged in apparatus Soxhlet for 4 hours. The extraction was repeated to obtain a colorless methanolic extract (extraction until exhaustion). The extracts were combined and dried in a rotary evaporator (Büchi brand) at $50^{\circ} \mathrm{C}$.

A sample of $35.8 \mathrm{~g}$ of dried methanolic extract in a rotary evaporator (brand Buchi) was dissolved with distilled and deionized water (400 $\mathrm{ml}$ ). The aqueous solution was extracted with $1000 \mathrm{ml}$ of hexane and the mixture was separated in a separation funnel. The process was repeated. The aqueous and hexane fractions were obtained. The hexane fractions were pooled and dried in a 
rotary evaporator (Buchi trademark) at $50^{\circ} \mathrm{C}$ under vacuum and the fluid (HF) was analyzed.

\section{Chloroform fraction (CF)}

The resulting aqueous fraction from the hexane extraction was extracted with $1000 \mathrm{ml}$ of chloroform in duplicate. The mixture was separated in a separation funnel and the aqueous and chloroform fractions were obtained. The chloroform fraction was dried in a rotary evaporator (Buchi brand) at $50^{\circ} \mathrm{C}$ under vacuum. The resulting powder $(\mathrm{CF})$ was analyzed.

\section{Ethyl acetate fraction (EF)}

The resulting aqueous fraction from the chloroform extraction was extracted with $1000 \mathrm{ml}$ of ethyl acetate in duplicate. The mixture was separated in a separation funnel and the ethyl acetate (organic) fraction obtained was dried in a rotary evaporator (Buchi brand) at $50^{\circ} \mathrm{C}$ under vacuum. The powder (EF) was analyzed.

\section{Isobutanol fraction (IF)}

The resulting aqueous fraction from the ethyl acetate extract was extracted with $1000 \mathrm{ml}$ of isobutanol in duplicate and the fractions were separated in a separation funnel. The fraction with isobutanol dried using rotary evaporator (brand Buchi) at $50^{\circ} \mathrm{C}$ under vacuum. The resulting powder (IF) was analyzed.

\section{Aqueous fraction (AF)}

The quantity of the fraction referred to as IF (isobutanol) was reduced in a rotary evaporator and then dried on a bench-top spray dryer (Spray Dryer, Buchi) and the resulting powder (aqueous fraction - AF) was analyzed.
ANALYSIS

Glycosides

The glycosides compounds of leaves, extracts and fractions were assayed according to the method described by Dacome et al. 2005.

\section{Total phenolic compounds}

The phenolic compounds of leaves, extracts and fractions were assayed according to the method described by Singleton et al. 1999 (with modifications). A solution of $1 \mathrm{mg} / \mathrm{ml}$ of aqueous extract of the leaves was prepared to analyze the leaves. For the extract analysis, a solution of absolute ethanol (99.5\%) was prepared at a concentration of $0.5 \mathrm{mg} / \mathrm{ml}$ of ethanolic leaf extract by maceration, ethanolic leaf extract through Soxhlet and methanolic leaf extract through Soxhlet. The hexane, chloroform and isobutanol fractions were prepared at a concentration of $1 \mathrm{mg} / \mathrm{mL}$ of absolute ethanol. The ethyl acetate fraction was solubilized in ethanol at a concentration of $0.1 \mathrm{mg} /$ $\mathrm{ml}$. The concentration of phenolic compounds was expressed as mg of gallic acid equivalents (GAE) per extract/g using a standard curve prepared with water for the analysis of leaves (aqueous extract) $(0-30 \mu \mathrm{g} / \mathrm{ml})$ and in ethanol for analysis of extract fractions $(0-80 \mu \mathrm{g} / \mathrm{ml})$.

\section{Total flavonoids}

The quantification of total flavonoids was determined by Jia et al. 1999 (with modifications). All extracts and fractions were prepared at a concentration of $1 \mathrm{mg} / \mathrm{ml}$ of ethanol, except the ethyl acetate fraction $(0,5 \mathrm{mg} / \mathrm{ml})$. The absorbance reading of samples was $510 \mathrm{~nm}$. Data were expressed as rutin and quercetin equivalents. 


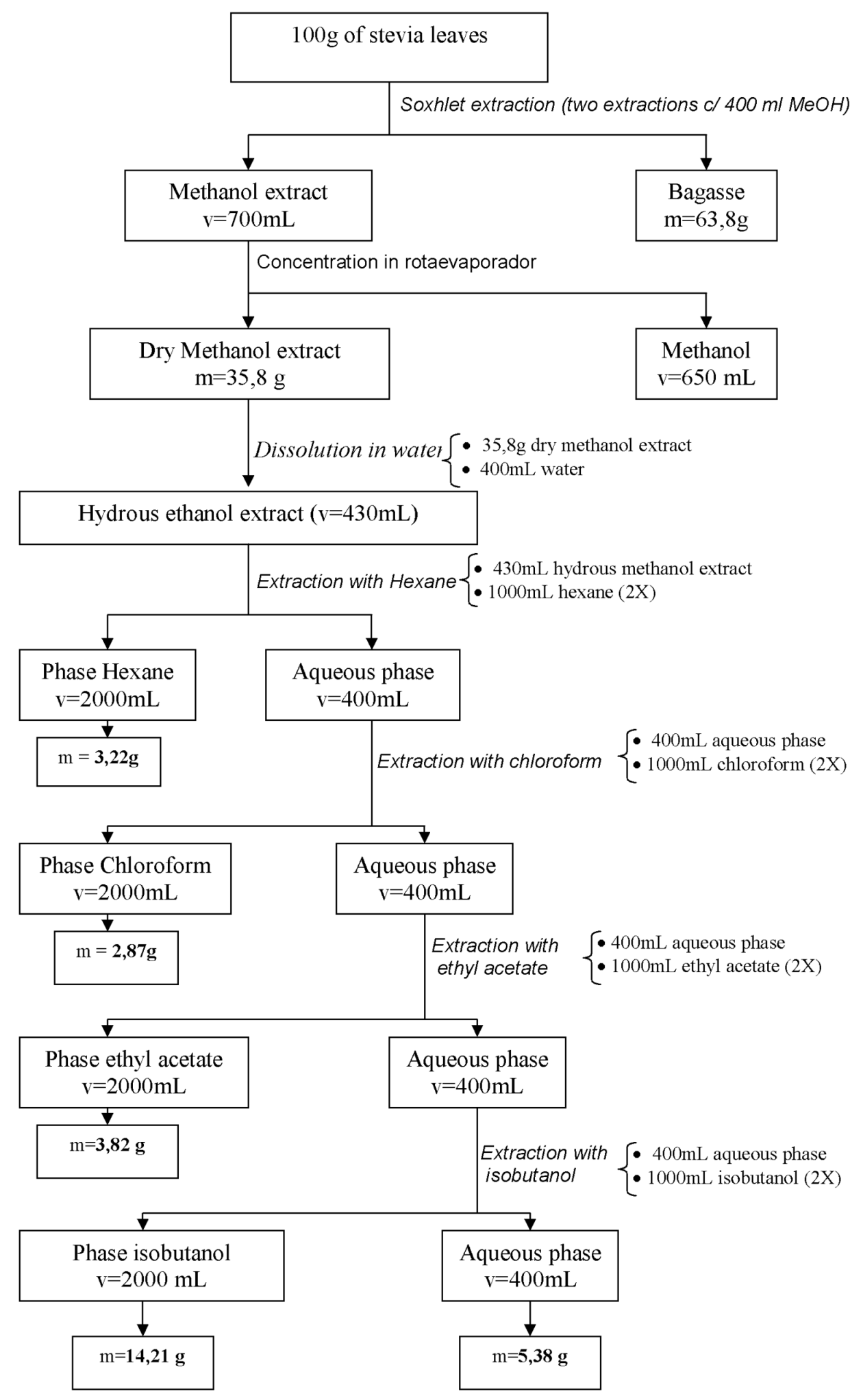

Figure 1 - Flow chart for obtaining stevia extract. 


\section{Antioxidant activity}

The elimination of free radical activity from the extracts and Stevia rebaudiana fractions of the seminal variety UEM-13 was measured by the ability to eliminate DPPH (Blios 1958, with modifications). The results were expressed as inhibition percentage of free radicals by the sample according to the following formula: $\%$ inhibition = $A_{0-} A_{t} A_{t} \times 100$. The symbol $A_{0}$ stands for control absorbance and $A_{t}$ for absorbance of each extract or fraction. All analyses were performed in triplicate and results expressed as mean values. Gallic acid was used as the standard.

\section{STATISTICAL ANALYSIS}

Each analysis was performed in triplicate. The results of all the analyses were expressed as mean \pm standard error of the mean and submitted to ANOVA followed by Tukey's test $(\mathrm{p}<0.05)$. We used the Statistical Analysis System (SAS, Institute Inc., Cary, North Carolina, United States, 2006) statistical software version 9.1.

\section{RESULTS AND DISCUSSION}

\section{TOTAL GLYCOSIDES}

Table I shows the glycoside content (stevioside and rebaudioside $\mathrm{A}$ and $\mathrm{C}$ ), total phenolics and flavonoids pooled from the leaves used in this study. Importantly, the Stevia leaves UEM-13 contain a higher content of rebaudioside A than of stevioside, and it is a variety of elite that can be reproduced by seeds, also increasing its advantage over crop varieties by cuttings. This is pioneering work with this cultivar. Stevia UEM-13 therefore presented a ratio RebA/Stev much higher (2.27) than the wild varieties that have inferiors values to 1 (Kovylyaeva et al. 2007, Gardana et al. 2010, Gupta et al. 2013, Madan et al. 2010). The new cultivar has significant levels of bioactive compounds when compared with other wild varieties (Gawel-Beben et al. 2015, Pasquel et al. 2000, Wölwer-Rieck 2012).

The Stevia leaves UEM-13 used in this study presented $14.8 \%$ of total glycosides. This seminal variety showed high rebaudiuoside A content, indicating to be an elite variety. Table II shows the extraction yield of glycosides observed in the extraction methods, total glycoside content (stevioside and rebaudioside A, C and D), phenolic compounds (gallic acid equivalents) and total flavonoids (quercetin equivalent). The ethanol extraction method by maceration presented low yield and low percentage of glycosides, when compared with the extraction method in Soxhlet apparatus. Both extracts showed significant amounts of phenolic compounds and flavonoids and a significant percentage of antioxidant activity; these results indicate that treatment with alcoholic solvents may contribute to the extraction of other substances present in the stevia leaves, extracting substantial amounts of glycosides. Periche et al. 2015 study effectives extraction procedures for maximization of the yield of steviol glycosides and total phenolic compounds as well as antioxidant activity in stevia extracts. The results showed significant correlations and experimental conditions greatly influence this achievement. The choice of solvent and extraction method, temperature, time and ratio changes the performance of the

TABLE I

Total glycoside content (stevioside and rebaudioside A and C) from Stevia UEM-13.

\begin{tabular}{cccccccc}
\hline & $\begin{array}{c}\text { Phenolics } \\
\text { compouns }\end{array}$ & Total flavonoids & Glycosides & Stev & RebA & Reb C & RebA/Stev \\
\hline Leaves & $2,36 \%$ & $17,63 \%$ & $14.8 \%$ & $4.0 \%$ & $9.1 \%$ & $1.7 \%$ & 2.27 \\
\hline
\end{tabular}

Stev $=$ Stevioside RebA= Rebaudioside $\mathrm{A} ; \mathrm{RebC}=$ Rebaudioside $\mathrm{C}$. 
extraction. This work indicates that the fractioning with different solvents can change the proportion of sweeteners and antioxidants, showing in most of them a negative correlation.

Pasquel et al. 2000 show that pretreatment of stevia leaves with solvents such as ethanol and $\mathrm{CO}_{2}$ prior to the conventional extraction process can improve the quality of the sweetener obtained, contributing to the reduction of the bitter aftertaste. Hexane, chloroform and ethyl acetate fractions do not contain significant concentrations of glycosides, unlike isobutanol that extracted $60.3 \%$ of sweeteners, making this the best solvent to extract higher yields of sweeteners in the industrial processes.

\section{TOTAL PHENOLIC COMPOUNDS}

The content of phenolic compounds present in the Stevia leaves UEM-13 (aqueous extract of leaves) was $23.61 \mathrm{mg} / \mathrm{g}$ GAE (Gallic Acid Equivalent). Figure 2 shows the concentration of phenolic compounds of the Stevia rebaudiana leaf extracts and fractions of the variety UEM-13. These results demonstrate the high antioxidant potential of the extracts from the Stevia leaves, particularly the methanol and ethyl acetate extracts $(107.08 \mathrm{mg} / \mathrm{g}$, $524.2 \mathrm{mg} / \mathrm{g}$, respectively). Shukla et al. 2009

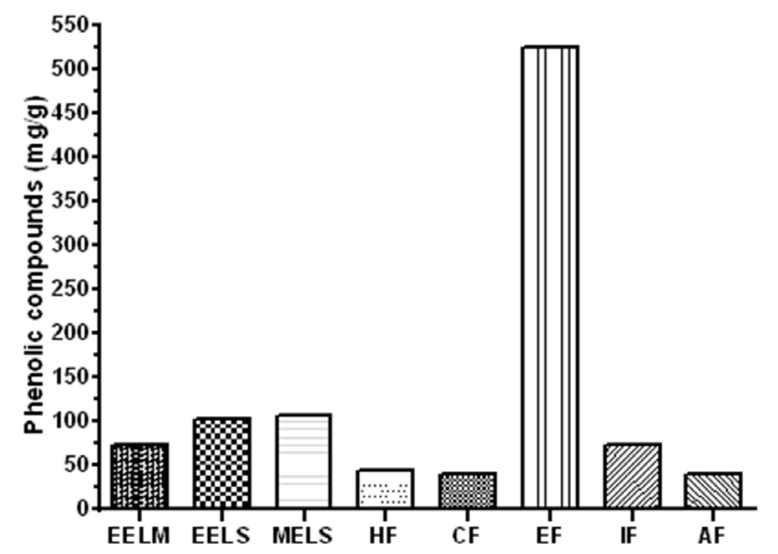

Figure 2 - Total phenolic extracts from Stevia leaves UEM13 expressed as $\mathrm{mg}$ of gallic acid equivalents per extract/g. The letters represent the following: EELM: Ethanolic Extract of Leaves (maceration); EELS: Ethanolic Extract of Leaves (Soxhlet); MELS: Methanolic Extract of Leaves (Soxhlet); HF: Hexane Fraction; CF: Chloroform Fraction; EF: Ethyl acetate Fraction; IF: Isobutanol Fraction, AF = Aqueous Fraction.

found $61.5 \mathrm{mg} / \mathrm{g}$ GAE from the ethanol extract of Stevia leaves through Soxhlet. Gawel-Beben et al. 2015 found similar values of phenolic compounds in ethanol extract of dried leaves from Stevia rabaudiana. The values found in the present study indicate that these compounds should be further evaluated for their antioxidant potential in food and drinks, and further demonstrates that the ethyl acetate fraction has the greatest potential for will provide additional benefits in terms of oxidative.

TABLE II

Total compunds present in the Stevia rebaudiana extracts and fractions.

\begin{tabular}{ccccc}
\hline Type of extract & $\begin{array}{c}\text { Extraction yield } \\
\mathbf{( g / 1 0 0 g )}\end{array}$ & $\begin{array}{c}\text { Total glycosides } \\
\mathbf{( g / 1 0 0 g})\end{array}$ & $\begin{array}{c}\text { Phenolics } \\
\text { compounds (g/100g) }\end{array}$ & Total flavonoids (g/g) \\
\hline EELM & $6.13 \pm 0,01$ & $26.0 \pm 0,01$ & $7.27 \pm 0,01$ & $0.28 \pm 0,02$ \\
EELS & $29.50 \pm 0,01$ & $31.8 \pm 0,01$ & $10.26 \pm 0,02$ & $0.32 \pm 0,01$ \\
MELS & $38.82 \pm 0,02$ & $30.5 \pm 0,05$ & $10.70 \pm 0,05$ & $0.35 \pm 0,05$ \\
HF & $8.99 \pm 0,01$ & $0.1 \pm 0,01$ & $4.47 \pm 0,01$ & $0.29 \pm 0,01$ \\
CF & $8.01 \pm 0,01$ & $1.1 \pm 0,04$ & $3.96 \pm 0,03$ & $0.26 \pm 0,02$ \\
EF & $10.67 \pm 0,02$ & $0.05 \pm 0,01$ & $52.42 \pm 0,03$ & $0.38 \pm 0,01$ \\
IF & $39.69 \pm 0,01$ & $70.8 \pm 0,02$ & $7.29 \pm 0,01$ & $0.24 \pm 0,01$ \\
AF & $15.02 \pm 0,01$ & $1.14 \pm 0,01$ & $2.33 \pm 0,01$ & $0.07 \pm 0,01$ \\
\hline
\end{tabular}

EELM: Ethanolic Extract of Leaves (maceration); EELS: Ethanolic Extract of Leaves (Soxhlet); MELS: Methanolic Extract of Leaves (Soxhlet); HF: Hexane Fraction; CF: Chloroform Fraction; EF: Ethyl Acetate Fraction; IF: Isobutanol Fraction, AF: Aqueous Fraction. 


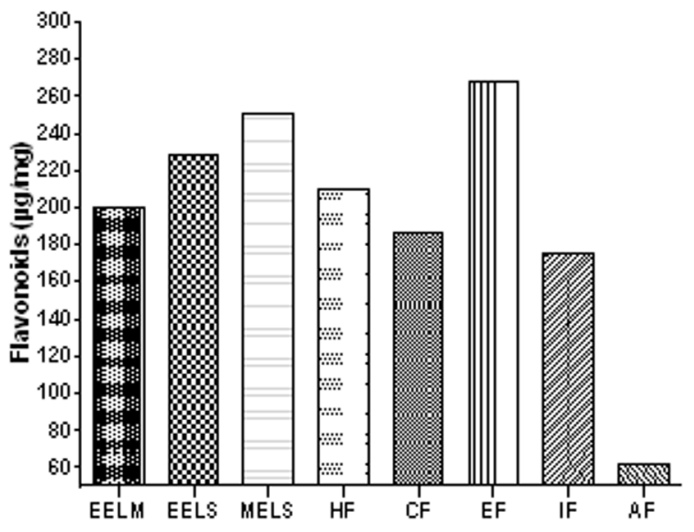

(a)

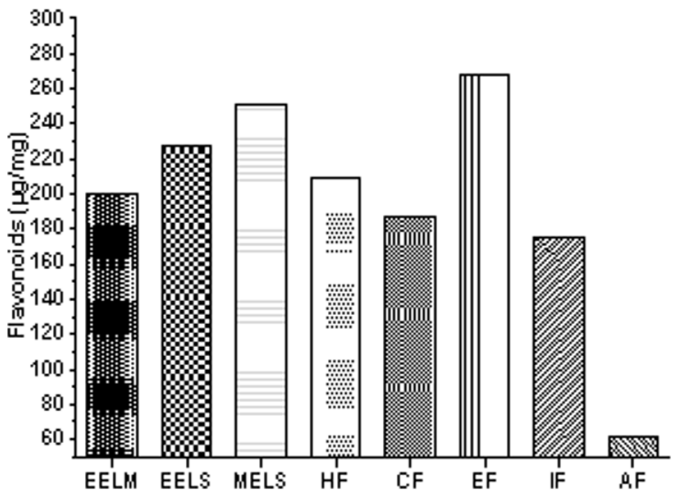

Figure 3 - Total flavonoid extracts from the Stevia leaves UEM-13 expressed as $\mu \mathrm{g}$ of quercetin equivalent per extract $/ \mathrm{mg}$ (a) and $\mu \mathrm{g}$ of rutin equivalents per extract/mg; (b) $\mu \mathrm{g}$ of quercetin equivalents per extract/mg. The letters represent the following: EELM: Ethanolic Extract of Leaves (maceration); EELS: Ethanolic Extract of Leaves (Soxhlet); MELS: Methanolic Extract of Leaves (Soxhlet); HF: Hexane Fraction; CF: Chloroform Fraction; EF: Ethyl acetate Fraction; IF: Isobutanol Fraction, AF = Aqueous Fraction.

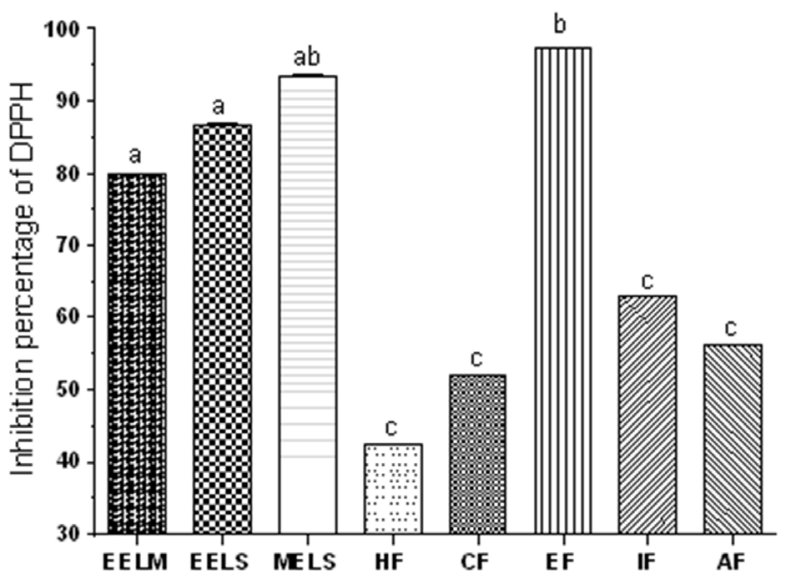

Figure 4 - Percentage of inhibition of DPPH radicals from leaf extracts of Stevia UEM-13 (1 mg/ml). Mean values with different superscript letters indicate significant differences $(\mathrm{P}$ $>0.05)$. The letters represent the following: EELM: Ethanolic Extract of Leaves (maceration); EELS: Ethanolic Extract of Leaves (Soxhlet); MELS: Methanolic Extract of Leaves (Soxhlet); HF: Hexane Fraction; CF: Chloroform Fraction; EF: Ethyl acetate Fraction; IF: Isobutanol Fraction, AF = Aqueous Fraction.

\section{TOTAL FLAVONOIDS}

Different concentrations of these compounds can be found in leaves, callus, and different Stevia rebaudiana extracts, depending on the conditions, type of solvent and extraction method used (Madan et al. 2010). In the present study the concentration of flavonoids present in the Stevia leaves UEM13 (aqueous extract) was $176.33 \mu \mathrm{g} / \mathrm{mg}$. After the extraction process, significant concentrations of flavonoids were found in the methanol and ethyl acetate extract, demonstrating the antioxidant potential of the extract (Figures $3 a$ and $3 b$ ).

\section{ANTIOXIDANT ACTIVITY}

Studies show that Stevia leaf extracts may exhibit high antioxidant potential (Periche et al. 2015). The antioxidant activity of the aqueous extract from the leaves of Stevia UEM-13 was $42.26 \%(1 \mathrm{mg} / \mathrm{ml})$. The Figure 4 shows the percentages of inhibition of DPPH radicals of the extracts evaluated in this study. It can be seen that, in general, all extracts showed important antioxidant potential, particularly the methanol extract of leaves obtained by extraction and through Soxhlet. The methanol extract and ethyl acetate fraction showed inhibition of DPPH radical of the $93.5 \%$ and $97.32 \%$ at a concentration of $1 \mathrm{mg} / \mathrm{ml}$. These extracts had higher levels of phenolic compounds and flavonoids which indicates high antioxidant activity. The $\mathrm{IC}_{50}$ for each extract (EEMF, EESF, MESF, HF, CF, EF, 
IF, AF) were $626.5 \mu \mathrm{g} / \mathrm{ml}, 576.70 \mu \mathrm{g} / \mathrm{ml}, 534.75$ $\mu \mathrm{g} / \mathrm{ml}, 1175 \mu \mathrm{g} / \mathrm{ml}, 963.02 \mu \mathrm{g} / \mathrm{ml}, 513.76 \mu \mathrm{g} / \mathrm{ml}$, 792. $64 \mu \mathrm{g} / \mathrm{ml}, 889.20 \mu \mathrm{g} / \mathrm{ml}$, respectively. The fraction with the hight potential is the ethyl acetate

\section{CONCLUSIONS}

This study shows for the first time the glycosides content, phenolic compounds and antioxidant activity of seminal variety from Stevia rebaudiana, Stevia UEM-13, confirming that a variety with high RebA content and can be reproduced by seeds.

The evaluation of extraction and fractionation of this plant using different solvents and methodologies resulted in extracts of different antioxidant capacity, which can be used to enrich the literature and contribute to their application in foods, pharmaceuticals and cosmetics. A diet rich in antioxidants may contribute significantly to prevent degenerative diseases, cardiovascular and metabolic diseases. Thus, natural and industrialized foods enriched with flavonoids and phenolic compounds contribute to the reduction of these diseases. The present study showed that ethanol, methanol and ethyl acetate extracts of Stevia rebaudiana leaves (Stevia UEM-13) have a great potential antioxidant and so can be used as possible additives to enhance the functionality of food and beverages.

\section{ACKNOWLEDGMENTS}

The authors thank the State University of Maringa and Coordenação de Aperfeiçoamento de Pessoal de Nível Superior (CAPES) agency. The authors declare that they have no conflict of interest.

\section{REFERENCES}

ABUDULA R, MATCHKOV VV, JEPPENSEN PB, NILSSON H, AALKJÆR C AND HERMANSEN K. 2008. Rebaudioside A directly stimulates insulin secretion from pancreatic beta cells: a glucose-dependent action via inhibition of ATP-sensitive $\mathrm{K}^{+}$-channels. Diabetes Obes Metab 10: 1074-1085.
ALVAREZ M AND COUTO AAC. 1994. Processo de fracionamento dos componentes das folhas de Stevia rebaudiana (Bert.) Bertoni. Fundação Universidade Estadual de Maringá, Banco do Brasil. Pedido de privilégio no Brasil, protocolo $\mathrm{n}^{\circ} 84.02 .752$.

BLIOS MS. 1958. Antioxidant determinations by the use of a stable free radical. Nature 26: 1199-1200.

CARAKOSTAS MC, CURRY LL, BOILEAU AC AND BRUSICK DJ. 2008. Overview: The history, technical function and safety of rebaudioside A, a naturally occurring steviol glycoside, for use in food and beverages. Food Chem Toxicol 46: 1-10.

CHAN P, LINSON B, CHEN Y, LIU J, HSIEH M AND CHENG J. 2000. A double blind placebo-controlled study of the effectiveness and tolerability of oral stevioside in human hypertension. Br J Clin Pharmacol 50: 215-220.

DACOME AS, SILVA CC, COSTA CEM, FONTANA JD, ADELMANN J AND COSTA SC. 2005. Sweet diterpenic glycosides balance of a new cultivar of Stevia rebaudiana (Bert.) Bertoni: Isolation and quantitative distribution by chromatographic, spectroscopic, and eletrophoretic methods. Process Biochemistry 40: 3587-3594.

GARDANA C, SCAGLIANTI M AND SIMONETTI P. 2010. Evaluation of steviol and its glycosides in Stevia rebaudiana leaves and commercial sweetener by ultra-high-performance liquid chromatography-mass spectrometry. J Chromatogr A 1217(9): 1463-1470.

GAWEL-BEBEN K, BUJAK T, NIZIOL-LUKASZEWSKA Z, ANTOSIEWICZ B, JAKUBEZYK A, KARAS M AND RYBRZYNSKA K. Stevia rebaudiana Bert. 2015. Leaf Extracts as a Multifunctional Source of Natural Antioxidants. Molecules 20: 5468-5486.

GUPTA E, PURWAR S, SUNDARAM S AND RAI GK. 2013. Nutritional and therapeutic values of Stevia rebaudiana: A review. J Med Plants Res 7(46): 3343-3353.

JIA Z, TANG M AND WU J. 1999. The determination of flavonoid contents in mulberry and their scavenging effects on superoxide radicals. Food chem 64: 555-559.

KAWSHIK R, PRADEEP N, VAMSHI V, GEETHA M AND USHA A. 2010. Nutrient Composition of cultivated stevia leaves and the influence of polyphenols and plant pigments on sensory and antioxidant properties of leaf extracts. J Food Sci Technol 47: 27-33.

KOVYLYAEVA GI, BAKALEINIK GA, STROBYKINA YU, GUBSKAYA VI, SHARIPOVA RR, AL'FONSOV VA, KATAEV VE AND TOLSTIKOV AG. 2007. Glycosides from Stevia rebaudiana. Chem Nat Compd 43(1): 81-85.

MADAN S, AHMAD S, SINGH GN, KOHLI K, KUMAR Y, SINGH R AND GARG M. 2010. Stevia rebaudiana (Bert.) Bertoni - A review. Indian J Nat Prod Resour 1(3): 267-286.

PASQUEL A, MEIRELES MAA, MARQUES MOM AND PETENATE AJ. 2000. Extraction of stevia glycosides with 
$\mathrm{CO}_{2}+$ water, $\mathrm{CO}_{2}+$ ethanol, and $\mathrm{CO}_{2}+$ water + ethanol. Braz J Chem Eng 17(3): 271-282.

PERICHE A, CASTELLÓ ML, HEREDIA A AND ESCRICHE I. 2015. Influence of Extraction Methods on the Yield of Steviol Glycosides and Antioxidants in Stevia rebaudiana Extracts. Plant Foods Hum Nutr 70(2): 119127.

SHUKLA S, MEHTAA, BAJPAI VK AND SHUKLA S. 2009. In vitro antioxidante activity and total phenolic content of ethanolic leaf extract of Stevia rebaudiana Bert. Food Chem Toxicol 47: 2338-2343.

SINGLETON VL, ORTHOFER R AND LAMUELARAVENTOS RM. 1999. Analysis of total phenols and other oxidation substrates and antioxidants by means folin-ciocalteu reagentes. Methods Enzymol 299: 152178.

TADHANI MB, PATEL VH AND SUBHASH R. 2007. In vitro antioxidant activities of Stevia rebaudiana leaves and callus. J Food Compost Anal 20: 323-329.

WILLIAMS LD AND BURDOCK GA. 2009. Genotoxicity studies on a high-purity rebaudioside A preparation. Food Chem Toxicol 47: 1831-1836.

WÖLWER-RIECK U. 2012. The Leaves of Stevia rebaudiana (Bertoni), Their Constituents and the Analyses Thereof: A Review. J Agric Food Chem 60: 886-895. 